\title{
The Rationale and Efficacy of Primary and Secondary Prevention in Adenocarcinomas of the Upper Gastrointestinal Tract
}

\author{
Jan Bornschein ${ }^{\mathrm{a}}$ Elizabeth L. Bird-Lieberman ${ }^{\mathrm{a}}$ Peter Malfertheiner ${ }^{\mathrm{b}}$ \\ aTranslational Gastroenterology Unit, John Radcliffe Hospital, Oxford University Hospitals, Oxford, UK; \\ ${ }^{b}$ Department of Gastroenterology, Hepatology and Infectious Disease, Otto-von-Guericke University, \\ Magdeburg, Germany
}

\section{Keywords}

Gastric cancer · Helicobacter pylori · Intestinal metaplasia ·

Barrett's oesophagus · Point of no return

\begin{abstract}
While the primary risk factor for oesophageal adenocarcino$\mathrm{ma}(\mathrm{OAC})$ and its precursor lesion Barrett's oesophagus (BO) is gastro-oesophageal reflux, the infection with Helicobacter pylori (H. pylori) is the dominant risk factor for gastric cancer. Reduction of reflux by dietary measures and proton pump inhibitors has some merits in OAC prevention, and the chemopreventive effect of Aspirin and statins is being widely investigated; however, improved outcome in OAC occurs primarily as the result of secondary prevention. Early detection of neoplastic lesions in Barrett's metaplasia can be achieved by surveillance endoscopies. Novel endoscopic imaging modalities carry similar importance as the endoscopic treatment techniques as without detection of early lesions, therapy cannot be applied. Minimally invasive approaches
\end{abstract}

are currently being investigated to identify patients with $\mathrm{BO}$ who are at particular risk of neoplastic progression. While dietary factors also play an important role in the prevention of gastric cancer and chemoprevention seems to be promising, the most beneficial effect has been shown for the eradication of H. pylori infection, which results in at least a one third reduction of gastric cancer risk. This effect can be further improved if the eradication takes place prior to the development of pre-neoplastic gastric conditions such as mucosal atrophy or intestinal metaplasia (IM). The definition of the "point of no return", after which eradication is less effective, is of high importance, although H. pylori eradication can still be beneficial even at more advance stages of mucosal changes. For this reason, patients with advanced atrophy and IM should undergo endoscopic surveillance in the same way as patients with $\mathrm{BO}$. There is also need for development of non-invasive tests to identify patients at high risk of progression to gastric cancer to improve outcome of these surveillance approaches.

\section{KARGER}

(c) 2019 S. Karger AG, Basel

E-Mail karger@karger.com

www.karger.com/ddi
Prof. Dr. Drs. h.c. Peter Malfertheiner

Department of Gastroenterology, Hepatology and Infectious Disease Otto-von-Guericke University

Leipziger Street 44, DE-39120 Magdeburg (Germany)

E-Mail peter.malfertheiner@med.ovgu.de 


\section{Oesophageal Adenocarcinoma}

Trends in the incidence of oesophageal squamous cell cancer and adenocarcinoma are changing in the Western world. Oesophageal adenocarcinoma (OAC) has become the predominant type with a constant rise in incidence over the last 30 years [1-3]. OAC is associated with chronic gastro-oesophageal reflux of acid and bile and Barrett's metaplasia is the well-established precancerous condition [4]. Unfortunately, 95\% of patients are not known to have Barrett metaplasia at the time of OAC diagnosis [5]. Risk factors for OAC include age $>50$ years, male gender, obesity, smoking and Caucasian ethnicity [6]. Measures of primary prevention focus on diet and reflux control in those with symptoms, but there are no strategies for general screening. Secondary prevention aims at early detection of dysplasic lesions and OAC within the framework of endoscopic surveillance of Barrett's oesophagus (BO) and endoscopic treatment of early dysplastic lesions.

\section{Primary Prevention}

Gastroesophageal Reflux

Although the association of pathological gastro-oesophageal reflux and development of Barrett's oesophagus has been clearly established, further factors play a role in the progression of $\mathrm{BO}$ towards neoplasia [5]. Identification of patients at risk is still a major issue since progression towards dysplasia and cancer does occur also in absence of classic reflux symptoms [7]. However, intensity, frequency and duration of chronic reflux symptoms remain important risk indicators for progression. A Swedish case-control study showed an OR of 2.0 for cardia cancer and of 7.7 for distal oesophageal cancer in patients with recurrent reflux symptoms compared to patients without symptoms. A higher prevalence of reflux symptoms in patients with cancer in the distal oesophagus or at the gastro-oesophageal junction (GOJ) compared to controls was also reported in studies from the United States $[8,9]$. Another population-based case-control study from the United States showed an OR for OAC of 3.61 (95\% CI 2.49-5.25) in the presence of reflux symptoms, of 5.85 (95\% CI 3.18$10.75)$ in case of a hiatus hernia and of 8.11 (95\% CI 4.75-13.87) in case of both factors being present [10]. There is a clear need for non-invasive tools for identifying patients at risk who do not present with typical symptoms $[5,11]$. Blood-based markers would be most feasible regarding clinical applicability. There are also efforts to assess the usefulness of breath tests for analy- sis of volatile markers as well as community-based application of minimally invasive sponge- or brush-based techniques.

\section{Chemoprevention}

Exposure of the distal oesophagus to gastric acid and bile induces chemical irritation and a local inflammatory reaction. Bile salts, in particular, display properties that interfere with the barrier function of cell membranes and with damage to DNA by increase of intracellular radical oxygen species. A modified local immune response may also contribute, as exposure to bile has led to acceleration of carcinogenesis in the experimental setting in mice [12].

A meta-analysis of 7 observational studies including 2,813 Barrett's patients and 317 patients with OAC showed a significantly protective effect by use of proton pump inhibitors (PPI; OR 0.29; 95\% CI 0.12-0.79). This effect is not shown for histamine 2 receptor antagonists (H2RA) [13]. A nested case-control study in more than 1,000 US Veterans confirmed this effect, which was even more obvious with higher doses of PPI (OR 0.11 ; $95 \%$ CI 0.04-0.36) [14]. Recently, the effect of PPI on the prevention of further progression of $\mathrm{BO}$ has been prospectively assessed in the AspECT trial [15]. A total of 2,557 patients were recruited in $84 \mathrm{UK}$ centres and one in Canada before randomisation in a 2-by-2 factorial design to assess the long-term effect of Esomeprazole ( $20 \mathrm{vs} .40 \mathrm{mg}$ ) each with or without Aspirin (300 mg). The primary endpoint of this study was a composite of time to all-cause mortality, incidence of OAC and of high grade dysplasia (HGD), all adjusted for age, length of the Barrett's segment and presence of intestinal metaplasia (IM). During a median follow-up time of 8.9 years, 313 primary events occurred. High-dose PPI (40 mg Esomeprazole) was superior to low dose $(20 \mathrm{mg})$ with regards to protection from dysplastic or neoplastic lesions. The use of Aspirin was beneficial only when patients with the use of further NSAIDs at inclusion were censored. The combination of high dose PPI plus Aspirin showed the best outcome regarding chemoprevention of $\mathrm{BO}$ and the complications mentioned above as included in the composite primary endpoint [15]. The number needed to treat to prevent a primary event was 34 for PPI and 43 for Aspirin. An effect for other NSAIDs could not be confirmed $[14,16]$.

A protective effect against the development of $\mathrm{BO}$ has also been attributed to statins. A case-control study and consecutive meta-analysis by Beales et al. [17] showed a risk reduction by nearly $40 \%$ for statin users (OR 0.62 ; 95\% CI 0.37-0.93). The effect was even stronger when 
statins were combined with Aspirin (OR 0.43; 95\% CI 0.21-0.89). These results were similar to a case-control study investigating the protective effect of statins against the development of OAC in US Veterans with BO, furthermore confirming a dose-dependent effect [18]. The effect on protection against $\mathrm{BO}$ was more pronounced in obese patients [19].

Other candidate drugs proposed for prevention of $\mathrm{OAC}$, such as metformin, have not been confirmed to have a beneficial effect [20-22].

\section{Obesity}

Obesity is a definite risk factor for OAC (relative risk 2.73; 95\% CI 2.16-3.46) [23]. A meta-analysis of observational studies demonstrated a risk increase for cardia cancer by $50 \%$ in Western populations (OR 1.55 ; 95\% CI 1.31-1.84) [24]. There is a positive correlation between the risk of cancer at the GOJ and increasing BMI [25]. In contrast, recent data from the EPIC trial showed no association between OAC and BMI or waist circumference, but a positive result for hip circumference [26]. Observations from the Chinese Linxian cohort, which included almost 30,000 individuals showed a decreased risk for non-cardia gastric-cancer, but no association with cardia cancers (usually referring to Siewert type 2 and 3 cancers at the GOJ) [27]. Nevertheless, obesity is an established risk factor for chronic gastro-oesophageal reflux disease and therefore likely to contribute to oesophageal carcinogenesis.

\section{Secondary Prevention}

Secondary prevention refers to approaches that enable the early detection of neoplastic lesions, which leads to curative - and often minimally invasive - treatment. $\mathrm{BO}$ and its endoscopic surveillance, similar to colonic polyp surveillance, is an excellent example of an effective strategy.

\section{Surveillance of BO}

Endoscopic surveillance of patients with $\mathrm{BO}$ is the key to improving outcome. The absolute risk of progression of $\mathrm{BO}$ to OAC is very low $(0.2-0.7 \%$ per patient per year) [28-30]. There is an established association of the length of $\mathrm{BO}$ and its risk of progression. Data from 1,175 patients who were followed-up at 5 tertiary centres in the United States demonstrated a risk increase of $28 \%$ per each additional $\mathrm{cm}$ of Barrett's length [31]. A study by Pohl et al. [32] showed transition rates towards more advanced lesions in $0.22 \%$ of patients with segments $\geq 3 \mathrm{~cm}, 0.03 \%$ in patients with segments $\geq 1 \mathrm{~cm}$ and $<3 \mathrm{~cm}$, and 0.01 if the metaplastic segment was $<1 \mathrm{~cm}$. This resulted in a calcu-

Early Detection and Prevention of Upper Gastrointestinal Cancer lated number-needed-to survey of 450 for segments $>3 \mathrm{~cm}, 3,440$ between $1-3 \mathrm{~cm}$ and 12,364 if the area was $<1 \mathrm{~cm}$. There is also evidence that the length of $\mathrm{BO}$ is established at index endoscopy and does not change over time [33].

The risk of progression towards invasive neoplasia increases substantially with presence of dysplasia. While there are conflicting results for lesions "indefinite for dysplasia" and low grade dysplasia (LGD) [30, 34, 35], the progression rates increase to $25 \%$ when HGD is present [36].

Endoscopic surveillance at regular intervals aims to increase the proportion of patients in whom neoplastic lesions are detected at an early stage, that is, HGD or early cancer that is confined to the mucosa so that curative, endoscopic treatment can be given. However, the intervals and strategies vary between countries, mainly due to contradictory evidence in terms of the benefits of surveillance. Corley et al. [37] could not confirm a significantly reduced risk of death from OAC associated with surveillance (adjusted OR 0.99; 95\% CI 0.36-2.75), disagreeing with previous studies. However, a meta-analysis of 51 studies including more than 11,000 patients, demonstrated that endoscopic surveillance of patients with non-dysplastic BO increases the likelihood for early detection of neoplastic lesions and therefore reduces mortality by more than $61 \%$ (mortality risk 0.386 ; $95 \%$ CI $0.242-0.617$ ) [38]. In a multicentre prospective cohort $(n=783), 53 \mathrm{pa-}$ tients developed HGD or OAC during surveillance with OAC being diagnosed at an earlier stage compared to diagnosis in the general population $(p<0.001)$ [39]. Patient-related factors (e.g., Barrett's length, histopathological characteristics) need to be taken into account to further tailor individual risk-adapted surveillance intervals. The so-called Seattle protocol suggests that targeted biopsies be taken from visible lesions suspicious for dysplastic changes of the mucosa, as well as 4 "random" quadrantic biopsies be taken at $2-\mathrm{cm}$ intervals over the entire extent of the Barrett's segment [40].

The recent statement of the European Society for Gastrointestinal Endoscopy recommends surveillance every 3 years for patients with segments of 3-10 and every 5 years for those with a Barrett's length of $1-3 \mathrm{~cm}$. Metaplastic segments $<1 \mathrm{~cm}$ should not be subject to surveillance [41]. If the segment exceeds $10 \mathrm{~cm}$, then the patient should be referred to a specialised centre. This is also the case if endoscopic treatment is required. These specialised centres are defined by an annual case load of more than 10 new patients requiring endoscopic treatment of HGD and early OAC per year, a number of 30 supervised 
endoscopic resections per year, specific Barrett's MDTs and an adequate database. Endoscopists and histopathologists should have undergone specific training [41]. It is of note that any degree of dysplasia (both LGD and HGD) requires confirmation by a second expert GI pathologist.

Endoscopic Treatment of Precancerous and Early

Neoplastic Lesions

Dysplasia (confirmed LGD and HGD) and early cancer in the distal oesophagus need to be removed after discussion at a multidisciplinary team meeting. This is best achieved by a multimodal endoscopic approach with endoscopic mucosal resection of any visible lesion, followed by ablation of the remaining Barrett's segment. As recommended by national and European guidelines, the current gold standard for mucosal ablation is radiofrequency ablation, but for small segments argon plasma coagulation can be used $[41,42]$. This strategy is both safe and effective resulting in minimally invasive treatment at early stage and thus fewer patients dying from OAC [43-46]. Treatment of LGD can be recommended under certain conditions, since it can be associated with significant progression rates. It is vital that LGD is confirmed by at least 2 independent expert pathologists as already indicated above [47, 48].

Endoscopic follow-up of patients even after complete eradication of the dysplastic/metaplastic segment is recommended in current guidelines [41, 49, 50]. Buried glands and recurrence of metaplasia can thus be detected and treated early $[51,52]$.

\section{Advanced Endoscopic Imaging}

Sampling error from random biopsy sampling according to the Seattle protocol carries significant limitations, mostly due to the fact that only a small area of the metaplastic segment can be assessed with these small tissue samples. The use of more sophisticated endoscopic techniques for the assessment of the Barrett's mucosa is encouraged. They include narrow band imaging or autofluorescence imaging for targeted biopsies of suspicious areas that might otherwise have been missed. There are also ongoing efforts to improve risk stratification by established standard methods of virtual chromoendoscopy and magnifying endoscopy [53]. Combination with Histopathological/molecular markers should then further increase the amount of information that enables further tailored surveillance (e.g., p53, p16, cyclin A and altered ploidy) $[54,55]$.

Similarly, confocal laser endomicroscopy allows the real-time detection of intestinalised epithelium and even dysplastic changes and this can also be combined with tis- sue based biomarkers, resulting in excellent performance compared to standard histopathology $[56,57]$. An alternative approach to classical tissue-based assessment of biomarkers is the application of molecular probes that can be viewed during endoscopy in real-time. One such approach takes advantage of the altered glycosylation patters of the mucosal surface during the progression towards cancer which can be imaged with a fluorescent lectin [58]. However, these techniques are not yet ready for routine clinical practice and are mainly explored at academic centres.

\section{New Approaches}

New approaches utilise techniques that enable more "universal" sampling of the Barrett's mucosa to minimise sampling errors. Brushing techniques were combined with computer-assisted read-out systems (EndoCDx ${ }^{\odot}$ system) to increase the diagnostic yield and more consistent inter-observer agreement $[59,60]$. Prospective assessment of this technique in 1,266 patients showed an increase in the detection rate for dysplasia of $87.5 \%$ compared to usual biopsy sampling approaches [61] resulting in a number-needed-to-test of 9.4 to detect one additional case with dysplasia [62].

Another sampling device that does not require endoscopic access of the lower oesophagus is the Cytospon$\mathrm{ge}^{\mathrm{TM}}$. This device is densely folded in a resolvable capsule that is swallowed and can then be retrieved by the string that is attached to it. While being retrieved, it gently scrapes the oesophagus collecting cells that can then be processed and evaluated. A prospective study in $1,110 \mathrm{pa}-$ tients showed sensitivity for BO of 79.9\% (87.2\% for segments $>3 \mathrm{~cm}$ ) and a specificity of $92.4 \%$. A combination with certain tissue markers also allows assessment for dysplasia [63]. This approach is safe and well accepted by patients, and may well be cost effective for communitybased screening [64-67].

\section{Gastric Adenocarcinoma}

Gastric cancer is a multifactorial disease and factors relating to immune response, diet and further environmental influences need to be balanced to maintain functional integrity of a healthy stomach [68]. Incidence rates of gastric cancer are decreasing (mainly in Western countries), but in spite of this, gastric adenocarcinoma remains a major health burden world-wide with nearly 2 thirds of new cases occurring in China, Japan and Korea. It is the third most common reason for cancer-related death, showing figures close to those for hepatocellular cancer, which 
ranks second [69]. In 2012, more than a quarter of the 951,000 gastric cancers were located at the GOJ (which includes the cardia). GOJ cancers show the most dramatic increase in incidence over the last 50 years [70]. The global incidence rates were $3.3 / 100,000$ for cardia cancers and 8.8/100,000 for non-cardia gastric cancer. Since most are diagnosed at an advanced stage, when only limited treatment options can be offered, there is imminent need for better means of prevention and early detection.

\section{Primary Prevention}

Diet

Alimentary factors have an impact on gastric cancer risk. Most evidence is available for high salt diets. Ingestion of salt in experimental animal settings causes gastritis by destroying the mucosal barrier leading to inflammation and damage such as diffuse erosion and degeneration [71-75]. A large number of human studies, including case-controls studies and prospective observational studies, confirmed the risk of high salt food in gastric carcinogenesis [76-80]. N-nitroso compounds (NOCs) are potent carcinogens and humans are exposed to various dietary NOCs by consumption of tobacco and even drinking water from certain sources [81]. NOCs are formed in vivo by the nitrosation of amides or amines in the stomach by nitrites. Nitrosamines are mainly found in cured meat products, smoked preserved food, and pickled and salt-preserved food [82]. Meta-analyses confirmed a positive association between tobacco consumption and an increased risk for gastric cancer. After smoking cessation, it takes about 10 years for the risk to return to that of the general population $[83,84]$. However, studies conducted with the inclusion of Helicobacter pylori (H. pylori) found that, only in the presence of $H$. pylori gastritis, were these other environmental factors able to express their deleterious carcinogenic effect $[82,85]$.

A protective effect has been attributed to Vitamins C, $\mathrm{A}$, and $\mathrm{E}$ as well as diets high in content of fruit and vegetables containing these factors. This is often referred to as a "Mediterranean diet". There are contradictory results on the effects of garlic consumption, whereas data is overall in favour of a protective effect by long-term consumption of green tea [86].

Overall, it can be stated that a classic Western diet seems to increase the risk for upper gastrointestinal cancers.

\section{Chemoprevention}

There is ongoing discussion about the increased cancer risk in patients on long-term PPI treatment, possibly related to the PPI induced hyper-gastrinaemia, which is also seen in the presence of H. pylori [87]. Data is conflicting [88]. There also seems to be no increase in the prevalence of pre-neoplastic changes of the gastric mucosa with long-term PPI treatment from a comprehensive Cochrane analysis in 2014 [89]. Secondary analysis of data from the SOPRAN and LOTUS trial in which some patients were treated with long-term PPI (vs. surgical reflux treatment) did not reveal any difference regarding preneoplastic changes of the stomach or neuroendocine neoplasias within 12 years of follow-up [90]. It has been discussed in the past that although patients on PPI have shown a higher prevalence of gastric cancer in some studies, this result is confounded by the fact that the PPI might have been prescribed for dyspeptic symptoms caused by pre-neoplastic and neoplastic changes in the first place.

Data published in 2018 shows results on a cohort of 63,397 patients from Hong Kong who received longterm PPI after $H$. pylori eradication [91]. PPI intake was associated with an increased risk for gastric cancer (hazard ratio [HR] 2.44; 95\% CI 1.42-4.20), which was not seen in patients who received H2RA. The risk further increased with the duration of PPI intake. However, the interpretation of these results requires caution, since a causal relationship cannot be inferred. It must also be considered that patients on PPI were older than non-PPI users (64.1 vs. 54.3 years) and that success of the initial H. pylori eradication was never confirmed [91]. Similar results were presented for a nationwide Swedish cohort study including nearly 800,000 patients showing also a threefold risk increased in the standardised incidence ratio (SIR) for gastric cancer among long-term PPI users (SIR 3.38; 95\% CI 3.23-3.53), in particular those under the age of 40 years (SIR 22.76; 95\% CI 15.94-31.52) [92]. There was no significant difference of this effect regarding cancer location. Patients on additional Aspirin showed a lower risk. Again, there was no risk associated with use of H2RA. It is of note that a subsequent analysis of the Hong Kong data also assessed the impact of combined use of PPI and Aspirin. While long-term PPI intake was associated with an increased risk of gastric cancer among non-Aspirin users (HR 3.73; 95\% CI 2.116.60), this was not the case for patients taking Aspirin in addition to PPI (HR 0.35; 95\% CI 0.04-2.74) [93]. The interaction between these drugs and the implication for cancer prevention require further elucidation. Overall, the current evidence is still inadequate to establish causal relationship, but PPI should only be used for the correct indication and at the lowest effective dose [94]. Long-term treatment or inappropriate dose escalation in non-responders should be avoided. 
As indicated above, intake of Aspirin and NSAIDs is suggested to have a protective effect due to reduction of the chronic inflammatory activity in the gastric mucosa [95]. However, evidence is not strong enough to give a general recommendation for intake of these compounds with the aim of cancer prevention, particularly in the view of an increased risk for gastro-duodenal ulcers as well as beneficial impact on the cardiovascular system. Most consistent was the effect for intake of Aspirin as shown in an analysis on 650,000 patients who took Aspirin for longer than 10 years resulting in a risk reduction of nearly 50\% [96]. Regular intake of Aspirin had to be maintained and the effect could not be confirmed for other NSAIDs as also reported in other studies $[97,98]$. Data on the benefits of COX-2 inhibitors is conflicting but show signs for improvement of pre-neoplastic conditions like chronic atrophic gastritis and gastric IM $[99,100]$. Comparison of these studies is often quite difficult due to hetergogeneous design, differing end-points and variation of inclusion and exclusion criteria.

Similar to the data presented above for OAC, several observational and case-control studies have demonstrated a protective effect of statins regarding the risk for gastric cancer development. Most studies show a risk reduction in a range of $30-40 \%$ [101-103]. However, it is not clear if there is a dose-dependent effect, also regarding the duration of treatment.

\section{H. pylori Eradication}

Infection with $H$. pylori is the most relevant risk factor for gastric cancer. The Kyoto consensus has recently defined $H$. pylori gastritis as an infectious disease that has to be eradicated when diagnosed [104]. The first meta-analysis that confirmed a preventive effect from eradication of $H$. pylori was published by Fuccio et al. [105] in 2009, stating a reduction of gastric cancer incidence by $35 \%$ analysing data from 6,695 patients. A population-based study from Taiwan including more than 4,000 individuals in which $78.2 \%$ of $H$. pylori could be eradicated confirmed a risk reduction for gastric cancer of about $25 \%$ [106]. Despite these positive findings, the actual effect was lower than anticipated. Thus, $H$. pylori eradication alone does not necessarily abolish gastric cancer risk. A prospective, randomised, double-blinded placebo-controlled eradication trial from China followed 1,630 patients for 7.5 years after intervention [107]. The primary endpoint of this study was missed with no statistically significant difference in gastric cancer incidence between the study arms. However, secondary analysis showed that adenocarcinoma only developed in patients who present- ed with pre-neoplastic changes (atrophy and/or IM) at study inclusion. When adjusted for these findings, the effect of $H$. pylori eradication was highly significant. So, patients with pre-neoplastic conditions at the time of eradication carry further the risk for gastric cancer development and this risk is associated with the degree and distribution of the respective changes [108-112].

There is great interest in the definition of the "point of no return" from which point, eradication treatment will not prevent further progression of pre-neoplastic changes. A nationwide cohort from the Netherlands demonstrated follow-up data over 5 years for more than 90,000 patients reporting a stepwise increase of the annual gastric cancer incidence from $0.1 \%$ in patients with chronic atrophic gastritis, to $0.25 \%$ in patients with IM, $0.6 \%$ in those with LGD and $6 \%$ in patients with HGD at index endoscopy [113]. Similarly, an observational cohort of 405,172 individuals in Sweden showed an incidence of gastric cancer in 1 out of 256 patients with initially normal mucosa, 1 out of 85 patients with gastritis, 1 out of 50 with atrophic gastritis, 1 out of 39 with IM and 1 out of 19 with dysplasia [114]. According to results from meta-analyses, eradication treatment can induce regression of atrophic changes of the gastric mucosa but has no impact on IM $[115,116]$, which is the reason for the presence of IM being currently considered to mark the "point of no return" [117]. Age alone should not be the rationale to decide if eradication is indicated. Older patients can still benefit from successful treatment of the infection. A recent analysis from Hong Kong showed a particular benefit of $H$. pylori treatment for patients of 60 years of age and older [118].

Although the eradication of $H$. pylori might not abolish gastric cancer risk in patients with advanced mucosal alterations, it might still confer a beneficial protective effect. Fukase et al. [119] reported a reduction of metachronous neoplasia by $H$. pylori eradication after endoscopic resection of early gastric cancer. This had been confirmed in a 2016 meta-analysis of 10 studies including 5,881 patients reporting a risk reduction of more than $60 \%$ (OR 0.39; 95\% CI 0.259-0.593; $p<0.001$ ) [120]. And final clarity on this issue was given by a recently published prospective double-blind, placebo-controlled randomised trial on 470 patients undergoing endoscopic resection of early gastric cancer or HGD [121]. Median follow-up time was 5.9 years with meta-chronous lesions occurring in 14 patients $(7.2 \%)$ in the treatment group and $27(13.4 \%)$ in the placebo group. This demonstrated a $50 \%$ risk reduction by eradication treatment (HR 0.50; $95 \%$ CI $0.26-0.94, p=0.03)$ [121]. 
Knowledge of further relevant factors that influence the effect of $H$ pylori eradication is expected from the interventional study that is currently being undertaken in the Chinese province of Linqu with international support [122]. The 185,000 inhabitants of this region were tested for H. pylori, and then randomised as to whether they received eradication prior to long-term follow-up. The study aims to demonstrate the feasibility of populationbased mass eradication and potential influencing factors. As indicated above, data from Taiwan already indicated the benefits of mass eradication in high incidence areas [123].

The best option for "global eradication" would be given by an $H$ pylori vaccine. A suitable vaccine is yet to be developed. A Chinese prospective, double-blind, placebo-controlled phase III study in children aged 6-15 years demonstrated a preventive effect in $70.8 \%$ by an oral recombinant vaccine [124]. These data remains to be confirmed and further discussion is warranted if $H$. pylori should be eradicated at such an early age. Data from another study testing an intramuscular vaccine in young healthy adult volunteers did not show adequate protection against the infection in this group. But interestingly, an enhanced immune reaction was seen in participants who received the vaccine (compared to placebo) [125]. All study participants were challenged with inoculation of a CagA positive H. pylori strain and it was interesting that the adult immune system proved to be quite competent to repel this infection with more than half of the subjects in the placebo arm failed to establish the infection.

\section{Secondary Prevention}

Secondary prevention of gastric cancer focuses on early detection of the disease when minimally invasive treatment can be offered with curative intention. Endoscopic surveillance of patients even after eradication of $H$. pylori is associated with the detection of early stage cancer and therefore better outcome [126]. A recent review by Rugge et al. [164] delivers a comprehensive overview on this topic. As outlined above, patients with IM and atrophic changes require regular endoscopic assessment because they have particular risk of progression towards cancer. The risk is increased three- to fivefold when atrophy and/ or IM is extensive [107, 127]. Extent and distribution of the mucosal alterations further influence the risk [114, 128-130]. The annual progression rate of advanced preneoplastic lesions is - similar to data from $\mathrm{BO}$ - around $0.3 \%$ [131]. Biopsies for the assessment of the gastric mucosa should be taken and histopathologically assessed ac-

Early Detection and Prevention of Upper Gastrointestinal Cancer cording to the updated Sydney classification [132]. Further stratification into the more recently developed Operative Link for Gastritis Assessment (OLGA) or Operative Link for Gastritis Assessment by IM systems allow even more precise individual risk assessment [133135]. Although Operative Link for Gastritis Assessment by IM shows a favourable interobserver variability, data for OLGA is more comprehensive and it has been suggested that a combination of both approaches be used [136-139]. Rugge et al. [140] recently presented data on 7,436 patients who were followed-up for a median of 6.6 years. At index endoscopy, $97.7 \%$ of the patients presented in OLGA stages 0 , I, and II, whereas only $2.3 \%$ showed high risk stages III and IV. And although there were 6 cases of incident gastric cancer in OLGA low risk patients, the majority of lesions developed in stages III and IV with these stages being confirmed as independent risk factors in multivariate analysis. The HR for OLGA III was as high as 712.4 (95\% CI 92.54-5,484.5) and for OLGA stage IV even higher (HR 1,450.7; 95\% CI 166.712,626.0) [140].

European guidelines recommend endoscopic surveillance every 3 years in case of advanced atrophy (or IM) [128]. Surveillance cannot be recommended in case of focal atrophy or IM, since the low progression rates $(<1.8 \%$ even after 10 years) result in inadequate cost-effectiveness ratios $[113,141]$. In addition to "random" biopsies according to the updated Sydney protocol, also targeted samples from visible lesions should be taken to increase the diagnostic yield [142]. Although the strategy of 3 -yearly endoscopic surveillance seems to be successful and cost effective also in a European setting, further prospective studies are required to deliver definite proof of its benefit [143-145]. The main issue remains the primary identification of patients who should undergo endoscopic surveillance. While population-based gastric cancer screening is established in Japan, Korea and Taiwan, this cannot be recommended for low incidence Western countries. Attempts are being made to improve the strategy by stricter selection criteria for patients undergoing surveillance [146] and by machine learning-based computational approaches for the assessment of endoscopic images, which might decrease the number of necessary biopsy samples [147].

\section{Serological Pre-Screening}

Serological pre-screening of individuals to identify those with the high likelihood for presence of pre-neoplastic conditions has since long been set in practice in Japan and more recently also in Korea. The best investi- 
gated surrogate marker is serum pepsinogen I and the pepsinogen/II-ratio. Watabe et al. [148] showed in a study of 9,293 Japanese subjects that the combination serum pepsinogen assessment and testing for anti- $H$. pylori antibodies was highly predictive for the development of gastric cancer [148]. Similar results were achieved in a study that considered only serum PG values and did not include $H$ pylori serology in the analysis $[149,150]$. A meta-analysis confirmed a risk-increase of gastric cancer by factor of 6 to 60 in cases with a pathological PG test and positive $H$. pylori serology [151]. Patients with positive test results should then undergo endoscopic assessment, a strategy that has been demonstrated to be effective in a Japanese meta-analysis of 40 studies with more than 300,000 participants [152]. The application of this strategy in certain regions in Asia led to a reduction of gastric cancer-related mortality by $76 \%$ [153].

A meta-analysis including data from European studies indicates similar results, although study heterogeneity does not allow to draw valid conclusions [154]. However, several cohort studies with follow-up up to 14 years showed promising results [149, 155-157]. Although serum PG assessment shows good diagnostic properties for the detection of gastric mucosal atrophy (sensitivity 74.4\%, 95\% CI 62.0-84.3; specificity 95.6\%, 95\% CI in 92.6-97.4) in a recent meta-analysis, this strategy cannot yet be recommended for countries with low incidence of gastric cancer [158]. Pre-selection of certain risk groups like smokers might be necessary to result in adequate protection against mortality from intestinal type gastric cancer and increase its cost effectiveness [159].

Similarly, a population-based "screen-and-treat" for H. pylori infection is currently not recommended for most regions in Europe [159]. Cost effectiveness could be improved if these tests are coupled with colorectal cancer screening, which has already been implemented in most European countries [160-162].

\section{Summary and Conclusion}

Prevention of OAC focuses on endoscopic surveillance of $\mathrm{BO}$ for detection of early dysplastic/neoplastic lesions, which are treatable by endoscopic modalities. Surveillance intervals depend on the macroscopic (e.g., length of the segment) and microscopic (e.g., presence and degree of dysplasia) characteristics of the meta-plastic segment. New methods for minimally invasive Barrett's detection are promising but still require validation of the merit in clinical routine settings. In the primary prevention of gastric cancer, the eradication of $H$. pylori infection remains the most powerful intervention. It cannot be emphasized enough that confirmation of successful eradication is a crucial part of any attempt to treat this disease. Better understanding of the biology of gastric pre-neoplastic lesions will allow a precise definition of the "point of no return" when eradication is no longer effective in halting the progression towards gastric neoplasia and thus selection of those patients who require endoscopic screening in regular intervals is required $[104,163]$. Future research will have to elaborate on simple methods for pre-selection of patients at high risk to allow their implementation in strategies and respect all demand of cost effectiveness.

\section{Disclosure Statement}

There are no conflicts of interest for the authors regarding the contents of this article.

\section{References}

1 Brown LM, Devesa SS, Chow WH. Incidence of adenocarcinoma of the esophagus among white Americans by sex, stage, and age. J Natl Cancer Inst. 2008 Aug;100(16):1184-7.

2 Lepage C, Rachet B, Jooste V, Faivre J, Coleman MP. Continuing rapid increase in esophageal adenocarcinoma in England and Wales. Am J Gastroenterol. 2008 Nov;103(11):2694-9.

3 Lepage C, Remontet L, Launoy G, Trétarre B, Grosclaude P, Colonna M, et al.; French network of cancer registries (FRANCIM). Trends in incidence of digestive cancers in France. Eur J Cancer Prev. 2008 Feb;17(1): 13-7.

4 Lagergren J, Bergström R, Lindgren A, Nyrén O. Symptomatic gastroesophageal re- flux as a risk factor for esophageal adenocarcinoma. N Engl J Med. 1999 Mar;340(11): 825-31.

5 Rubenstein JH, Thrift AP. Risk factors and populations at risk: selection of patients for screening for Barrett's oesophagus. Best Pract Res Clin Gastroenterol. 2015 Feb;29(1):4150.

6 Coleman HG, Bhat S, Johnston BT, McManus D, Gavin AT, Murray LJ. Tobacco smoking increases the risk of high-grade dysplasia and cancer among patients with Barrett's esophagus. Gastroenterology. 2012 Feb;142(2):23340.

7 Fan X, Snyder N. Prevalence of Barrett's esophagus in patients with or without GERD symptoms: role of race, age, and gender. Dig Dis Sci. 2009 Mar;54(3):572-7.

8 Velanovich V, Hollingsworth J, Suresh P, Ben-Menachem T. Relationship of gastroesophageal reflux disease with adenocarcinoma of the distal esophagus and cardia. Dig Surg. 2002;19(5):349-53.

9 Chak A, Faulx A, Eng C, Grady W, Kinnard $\mathrm{M}$, Ochs-Balcom H, et al. Gastroesophageal reflux symptoms in patients with adenocarcinoma of the esophagus or cardia. Cancer. 2006 Nov;107(9):2160-6.

10 Wu AH, Tseng CC, Bernstein L. Hiatal hernia, reflux symptoms, body size, and risk of esophageal and gastric adenocarcinoma. Cancer. 2003 Sep;98(5):940-8. 
11 Cook MB, Corley DA, Murray LJ, Liao LM, Kamangar F, Ye W, et al. Gastroesophageal reflux in relation to adenocarcinomas of the esophagus: a pooled analysis from the Barrett's and Esophageal Adenocarcinoma Consortium (BEACON). PLoS One. 2014 Jul; 9(7):e103508.

12 Quante M, Bhagat G, Abrams JA, Marache F, Good P, Lee MD, et al. Bile acid and inflammation activate gastric cardia stem cells in a mouse model of Barrett-like metaplasia. Cancer Cell. 2012 Jan;21(1):36-51.

13 Singh S, Garg SK, Singh PP, Iyer PG, El-Serag HB. Acid-suppressive medications and risk of oesophageal adenocarcinoma in patients with Barrett's oesophagus: a systematic review and meta-analysis. Gut. 2014 Aug;63(8):1229-37.

14 Tan MC, El-Serag HB, Yu X, Thrift AP. Acid suppression medications reduce risk of oesophageal adenocarcinoma in Barrett's oesophagus: a nested case-control study in US male veterans. Aliment Pharmacol Ther. 2018 Aug;48(4):469-77.

15 Jankowski JA, de Caestecker J, Love SB, Reilly G, Watson P, Sanders S, et al.; AspECT Trial Team. Esomeprazole and aspirin in Barrett's oesophagus (AspECT): a randomised factorial trial. Lancet. 2018 Aug;392(10145):400-8.

16 Thrift AP, Anderson LA, Murray LJ, Cook MB, Shaheen NJ, Rubenstein JH, et al. Nonsteroidal Anti-Inflammatory Drug Use is Not Associated With Reduced Risk of Barrett's Esophagus. Am J Gastroenterol. 2016 Nov; 111(11):1528-35

17 Beales IL, Dearman L, Vardi I, Loke Y. Reduced Risk of Barrett's Esophagus in Statin Users: Case-Control Study and Meta-Analysis. Dig Dis Sci. 2016 Jan;61(1):238-46.

18 Nguyen T, Duan Z, Naik AD, Kramer JR, ElSerag HB. Statin use reduces risk of esophageal adenocarcinoma in US veterans with Barrett's esophagus: a nested case-control study. Gastroenterology. 2015 Nov;149(6) 1392-8.

19 Nguyen T, Khalaf N, Ramsey D, El-Serag HB Statin use is associated with a decreased risk of Barrett's esophagus. Gastroenterology. 2014 Aug;147(2):314-23

20 Krishnamoorthi R, Borah B, Heien H, Das A, Chak A, Iyer PG. Rates and predictors of progression to esophageal carcinoma in a large population-based Barrett's esophagus cohort. Gastrointest Endosc. 2016 Jul;84(1):40-46.e7.

21 Becker C, Meier CR, Jick SS, Bodmer M. Casecontrol analysis on metformin and cancer of the esophagus. Cancer Causes Control. 2013 Oct;24(10):1763-70.

22 Agrawal S, Patel P, Agrawal A, Makhijani N, Markert R, Deidrich W. Metformin use and the risk of esophageal cancer in Barrett esophagus. South Med J. 2014 Dec;107(12):774-9.

23 Turati F, Tramacere I, La Vecchia C, Negri E. A meta-analysis of body mass index and esophageal and gastric cardia adenocarcinoma. Ann Oncol. 2013 Mar;24(3):609-17.

24 Kubo A, Corley DA. Body mass index and adenocarcinomas of the esophagus or gastric cardia: a systematic review and meta-analysis Cancer Epidemiol Biomarkers Prev. 2006 May; 15(5):872-8

25 Whiteman DC, Sadeghi S, Pandeya N, Smithers BM, Gotley DC, Bain CJ, et al.; Australian Cancer Study. Combined effects of obesity, acid reflux and smoking on the risk of adenocarcinomas of the oesophagus. Gut. 2008 Feb; 57(2):173-80.

26 Steffen A, Huerta JM, Weiderpass E, Buenode-Mesquita HB, May AM, Siersema PD, et al. General and abdominal obesity and risk of esophageal and gastric adenocarcinoma in the European Prospective Investigation into Cancer and Nutrition. Int J Cancer. 2015 Aug; 137(3):646-57.

27 Fan JH, Wang JB, Wang SM, Abnet CC, Qiao YL, Taylor PR. Body mass index and risk of gastric cancer: A 30-year follow-up study in the Linxian general population trial cohort. Cancer Sci. 2017 Aug;108(8):1667-72.

28 Hvid-Jensen F, Pedersen L, Drewes AM, Sørensen HT, Funch-Jensen P. Incidence of adenocarcinoma among patients with Barrett's esophagus. N Engl J Med. 2011 Oct;365(15): 1375-83.

29 Desai TK, Krishnan K, Samala N, Singh J, Cluley J, Perla $S$, et al. The incidence of oesophageal adenocarcinoma in non-dysplastic Barrett's oesophagus: a meta-analysis. Gut. 2012 Jul;61(7):970-6.

30 Curvers WL, ten Kate FJ, Krishnadath KK, Visser M, Elzer B, Baak LC, et al. Low-grade dysplasia in Barrett's esophagus: overdiagnosed and underestimated. Am J Gastroen terol. 2010 Jul;105(7):1523-30.

31 Anaparthy R, Gaddam S, Kanakadandi V, Alsop BR, Gupta N, Higbee AD, et al. Association between length of Barrett's esophagus and risk of high-grade dysplasia or adenocarcinoma in patients without dysplasia. Clin Gastroenterol Hepatol. 2013 Nov;11(11): 1430-6.

32 Pohl H, Pech O, Arash H, Stolte M, Manner $\mathrm{H}$, May A, et al. Length of Barrett's oesophagus and cancer risk: implications from a large sample of patients with early oesophageal adenocarcinoma. Gut. 2016 Feb;65(2): 196-201.

33 Moawad FJ, Young PE, Gaddam S, Vennalaganti P, Thota PN, Vargo J, et al. Barrett's oesophagus length is established at the time of initial endoscopy and does not change over time: results from a large multicentre cohort. Gut. 2015 Dec;64(12):1874-80.

34 Thota PN, Lee HJ, Goldblum JR, Liu X, Sanaka MR, Gohel T, et al. Risk stratification of patients with barrett's esophagus and lowgrade dysplasia or indefinite for dysplasia. Clin Gastroenterol Hepatol. 2015 Mar;13(3): 459-465.e1.

35 Duits LC, Phoa KN, Curvers WL, Ten Kate FJ, Meijer GA, Seldenrijk CA, et al. Barrett's oesophagus patients with low-grade dysplasia can be accurately risk-stratified after histological review by an expert pathology panel. Gut. 2015 May;64(5):700-6.
36 Kastelein F, van Olphen S, Steyerberg EW, Sikkema M, Spaander MC, Looman CW, et al.; ProBar-study group. Surveillance in patients with long-segment Barrett's oesophagus: a cost-effectiveness analysis. Gut. 2015 Jun;64(6):864-71.

37 Corley DA, Mehtani K, Quesenberry C, Zhao W, de Boer J, Weiss NS. Impact of endoscopic surveillance on mortality from Barrett's esophagus-associated esophageal adenocarcinomas. Gastroenterology. 2013 Aug;145(2):312-9.e1.

38 Qiao Y, Hyder A, Bae SJ, Zarin W, O’Neill TJ, Marcon NE, et al. Surveillance in Patients With Barrett's Esophagus for Early Detection of Esophageal Adenocarcinoma: A Systematic Review and Meta-Analysis. Clin Transl Gastroenterol. 2015 Dec;6(12):e131.

39 Kastelein F, van Olphen SH, Steyerberg EW, Spaander MC, Bruno MJ; ProBar-Study Group. Impact of surveillance for Barrett's oesophagus on tumour stage and survival of patients with neoplastic progression. Gut. 2016 Apr;65(4):548-54.

40 Levine DS, Blount PL, Rudolph RE, Reid BJ. Safety of a systematic endoscopic biopsy protocol in patients with Barrett's esophagus. Am J Gastroenterol. 2000 May;95(5):1152-7.

41 Weusten B, Bisschops R, Coron E, Dinis-Ribeiro M, Dumonceau JM, Esteban JM, et al. Endoscopic management of Barrett's esophagus: European Society of Gastrointestinal Endoscopy (ESGE) Position Statement. Endoscopy. 2017 Feb;49(2):191-8.

42 Fitzgerald RC, di Pietro M, Ragunath K, Ang Y, Kang JY, Watson P, et al.; British Society of Gastroenterology. British Society of Gastroenterology guidelines on the diagnosis and management of Barrett's oesophagus. Gut. 2014 Jan;63(1):7-42.

43 Haidry RJ, Butt MA, Dunn J, Banks M, Gupta A, Smart H, et al. Radiofrequency ablation for early oesophageal squamous neoplasia: outcomes form United Kingdom registry. World J Gastroenterol. 2013 Sep;19(36):6011-9.

44 Shaheen NJ, Sharma P, Overholt BF, Wolfsen HC, Sampliner RE, Wang KK, et al. Radiofrequency ablation in Barrett's esophagus with dysplasia. N Engl J Med. 2009 May;360(22): 2277-88.

45 Dulai PS, Pohl H, Levenick JM, Gordon SR MacKenzie TA, Rothstein RI. Radiofrequency ablation for long- and ultralong-segment Barrett's esophagus: a comparative long-term follow-up study. Gastrointest Endosc. 2013 Apr;77(4):534-41.

46 Wolf WA, Pasricha S, Cotton C, Li N, Triadafilopoulos G, Muthusamy VR, et al. Incidence of Esophageal Adenocarcinoma and Causes of Mortality After Radiofrequency Ablation of Barrett's Esophagus. Gastroenterology. 2015 Dec;149(7):1752-1761.e1.

47 Phoa KN, van Vilsteren FG, Weusten BL, Bisschops R, Schoon EJ, Ragunath K, et al. Radiofrequency ablation vs endoscopic surveillance for patients with Barrett esophagus and low-grade dysplasia: a randomized clinical trial. JAMA. 2014 Mar;311(12):1209-17. 
48 Small AJ, Araujo JL, Leggett CL, Mendelson $\mathrm{AH}$, Agarwalla A, Abrams JA, et al. Radiofrequency Ablation Is Associated With Decreased Neoplastic Progression in Patients With Barrett's Esophagus and Confirmed Low-Grade Dysplasia. Gastroenterology. 2015 Sep;149(3):567-76.e3.

49 di Pietro M, Fitzgerald RC; BSG Barrett's guidelines working group. Revised British Society of Gastroenterology recommendation on the diagnosis and management of Barrett's oesophagus with low-grade dysplasia. Gut. 2018 Feb;67(2):392-3.

50 Shaheen NJ, Falk GW, Iyer PG, Gerson LB; American College of Gastroenterology. ACG Clinical Guideline: Diagnosis and Management of Barrett's Esophagus. Am J Gastroenterol. 2016 Jan;111(1):30-50.

51 Vliebergh JH, Deprez PH, de Looze D, Ferrante $\mathrm{M}$, Orlent $\mathrm{H}$, Macken E, et al. Efficacy and safety of radiofrequency ablation of Barrett's esophagus in the absence of reimbursement: a multicenter prospective Belgian registry. Endoscopy. 2019 Apr;51(4):317-325.

52 Cotton CC, Haidry R, Thrift AP, Lovat L, Shaheen NJ. Development of Evidence-Based Surveillance Intervals After Radiofrequency Ablation of Barrett's Esophagus. Gastroenterology. 2018 Aug;155(2):316-326.e6.

53 Goda K, Fujisaki J, Ishihara R, Takeuchi M, Takahashi A, Takaki Y, et al. Newly developed magnifying endoscopic classification of the Japan Esophageal Society to identify superficial Barrett's esophagus-related neoplasms. Esophagus. 2018 Jun;15(3):153-9.

54 Boerwinkel DF, Di Pietro M, Liu X, Shariff MK, Lao-Sirieix P, Walker CE, et al. Endoscopic TriModal imaging and biomarkers for neoplasia conjoined: a feasibility study in Barrett's esophagus. Dis Esophagus. 2014 Jul; 27(5):435-43.

55 di Pietro M, Boerwinkel DF, Shariff MK, Liu $\mathrm{X}$, Telakis E, Lao-Sirieix P, et al. The combination of autofluorescence endoscopy and molecular biomarkers is a novel diagnostic tool for dysplasia in Barrett's oesophagus. Gut. 2015 Jan;64(1):49-56.

56 Ross-Innes CS, Becq J, Warren A, Cheetham RK, Northen H, O'Donovan M, et al. Wholegenome sequencing provides new insights into the clonal architecture of Barrett's esophagus and esophageal adenocarcinoma. Nat Genet. 2015 Sep;47(9):1038-46.

57 Tofteland N, Singh M, Gaddam S, Wani SB, Gupta N, Rastogi A, et al. Evaluation of the updated confocal laser endomicroscopy criteria for Barrett's esophagus among gastrointestinal pathologists. Dis Esophagus. 2014 Sep-Oct;27(7):623-9.

58 Bird-Lieberman EL, Neves AA, Lao-Sirieix P, O'Donovan M, Novelli M, Lovat LB, et al. Molecular imaging using fluorescent lectins permits rapid endoscopic identification of dysplasia in Barrett's esophagus. Nat Med. 2012 Jan;18(2):315-21.

59 Vennalaganti PR, Naag Kanakadandi V, Gross SA, Parasa S, Wang KK, Gupta N, et al.
Inter-Observer Agreement among Pathologists Using Wide-Area Transepithelial Sampling With Computer-Assisted Analysis in Patients With Barrett's Esophagus. Am J Gastroenterol. 2015 Sep;110(9):1257-60.

60 Kumaravel A, Lopez R, Brainard J, Falk GW Brush cytology vs. endoscopic biopsy for the surveillance of Barrett's esophagus. Endoscopy. 2010 Oct; $42(10): 800-5$

61 Johanson JF, Frakes J, Eisen D; EndoCDx Collaborative Group. Computer-assisted analysis of abrasive transepithelial brush biopsies increases the effectiveness of esophageal screening: a multicenter prospective clinical trial by the EndoCDx Collaborative Group. Dig Dis Sci. 2011 Mar;56(3):767-72

62 Anandasabapathy S, Sontag S, Graham DY Frist S, Bratton J, Harpaz N, et al. Computerassisted brush-biopsy analysis for the detection of dysplasia in a high-risk Barrett's esophagus surveillance population. Dig Dis Sci. 2011 Mar;56(3):761-6.

63 Ross-Innes CS, Debiram-Beecham I, O'Donovan M, Walker E, Varghese S, LaoSirieix P, et al.; BEST2 Study Group. Evaluation of a minimally invasive cell sampling device coupled with assessment of trefoil factor 3 expression for diagnosing Barrett's esophagus: a multi-center case-control study. PLoS Med. 2015 Jan;12(1):e1001780.

64 Januszewicz W, Tan WK, Lehovsky K, Debiram-Beecham I, Nuckcheddy T, Moist S, et al. Safety and Acceptability of Esophageal Cytosponge Cell Collection Device in a Pooled Analysis of Data From Individual Patients. Clin Gastroenterol Hepatol. 2019;17:647-656.e1.

65 Heberle CR, Omidvari AH, Ali A, Kroep S, Kong CY, Inadomi JM, et al. Cost Effectiveness of Screening Patients With Gastroesophageal Reflux Disease for Barrett's Esophagus With a Minimally Invasive Cell Sampling Device. Clin Gastroenterol Hepatol. 2017 Sep; 15(9):1397-1404.e7.

66 Ross-Innes CS, Chettouh H, Achilleos A, Galeano-Dalmau N, Debiram-Beecham I, MacRae S, et al.; BEST2 study group. Risk stratification of Barrett's oesophagus using a nonendoscopic sampling method coupled with a biomarker panel: a cohort study. Lancet Gastroenterol Hepatol. 2017 Jan;2(1):23-31.

67 Offman J, Muldrew B, O'Donovan M, Debiram-Beecham I, Pesola F, Kaimi I, et al.; BEST3 Trial team. Barrett's oESophagus trial 3 (BEST3): study protocol for a randomised controlled trial comparing the CytospongeTFF3 test with usual care to facilitate the diagnosis of oesophageal pre-cancer in primary care patients with chronic acid reflux. BMC Cancer. 2018 Aug;18(1):784.

68 Hunt RH, Camilleri M, Crowe SE, El-Omar EM, Fox JG, Kuipers EJ, et al. The stomach in health and disease. Gut. 2015 Oct;64(10): 1650-68.

69 Torre LA, Bray F, Siegel RL, Ferlay J, LortetTieulent J, Jemal A. Global cancer statistics, 2012. CA Cancer J Clin. 2015 Mar;65(2):87108.
70 Colquhoun A, Arnold M, Ferlay J, Goodman KJ, Forman D, Soerjomataram I. Global patterns of cardia and non-cardia gastric cancer incidence in 2012. Gut. 2015 Dec;64(12): 1881-8.

71 Konno-Shimizu M, Yamamichi N, Inada K, Kageyama-Yahara N, Shiogama K, Takahashi $\mathrm{Y}$, et al. Cathepsin $\mathrm{E}$ is a marker of gastric differentiation and signet-ring cell carcinoma of stomach: a novel suggestion on gastric tumorigenesis. PLoS One. 2013;8(2):e56766

72 Tatematsu M, Takahashi M, Hananouchi M, Shirai T, Hirose M. Protective effect of mucin on experimental gastric cancer induced by $\mathrm{N}$ methyl-N'-nitro-N-nitrosoguanidine plus sodium chloride in rats. Gan. 1976 Apr;67(2): 223-9.

73 Takahashi M, Hasegawa R. Enhancing effects of dietary salt on both initiation and promotion stages of rat gastric carcinogenesis. Princess Takamatsu Symp. 1985;16:169-82.

74 Yamamoto Y, Wang X, Bertrand D, Kern F, Zhang T, Duleba M, et al. Mutational spectrum of Barrett's stem cells suggests paths to initiation of a precancerous lesion. Nat Commun. 2016 Jan;7(1):10380.

75 Liu C, Russell RM. Nutrition and gastric cancer risk: an update. Nutr Rev. 2008 May;66(5): 237-49.

76 Glade MJ. Food, nutrition, and the prevention of cancer: a global perspective. American Institute for Cancer Research/World Cancer Research Fund, American Institute for Cancer Research, 1997. Nutrition. 1999 Jun;15(6): 523-6.

77 Lee SA, Kang D, Shim KN, Choe JW, Hong WS, Choi H. Effect of diet and Helicobacter pylori infection to the risk of early gastric cancer. J Epidemiol. 2003 May;13(3):162-8.

78 Ward MH, López-Carrillo L. Dietary factors and the risk of gastric cancer in Mexico City. Am J Epidemiol. 1999 May;149(10):925-32.

79 Kim HJ, Chang WK, Kim MK, Lee SS, Choi BY. Dietary factors and gastric cancer in Korea: a case-control study. Int J Cancer. 2002 Feb;97(4):531-5.

80 Shikata K, Kiyohara Y, Kubo M, Yonemoto K, Ninomiya T, Shirota $\mathrm{T}$, et al. A prospective study of dietary salt intake and gastric cancer incidence in a defined Japanese population: the Hisayama study. Int J Cancer. 2006 Jul; 119(1):196-201.

81 Tricker AR, Preussmann R. Carcinogenic Nnitrosamines in the diet: occurrence, formation, mechanisms and carcinogenic potential. Mutat Res. 1991 Mar-Apr;259(3-4):277-89.

82 Jakszyn P, Gonzalez C-A. Nitrosamine and related food intake and gastric and oesophageal cancer risk: a systematic review of the epidemiological evidence. World J Gastroenterol. 2006 Jul 21;12(27):4296-303.

83 Ladeiras-Lopes R, Pereira AK, Nogueira A, Pinheiro-Torres T, Pinto I, Santos-Pereira R, et al. Smoking and gastric cancer: systematic review and meta-analysis of cohort studies. Cancer Causes Control. 2008 Sep;19(7):689701 
84 Trédaniel J, Boffetta P, Buiatti E, Saracci R, Hirsch A. Tobacco smoking and gastric cancer: review and meta-analysis. Int J Cancer. 1997 Aug;72(4):565-73.

85 González CA, López-Carrillo L. Helicobacter pylori, nutrition and smoking interactions: their impact in gastric carcinogenesis. Scand J Gastroenterol. 2010;45(1):6-14.

86 Huang Y, Chen H, Zhou L, Li G, Yi D, Zhang $\mathrm{Y}$, et al. Association between green tea intake and risk of gastric cancer: a systematic review and dose-response meta-analysis of observational studies. Public Health Nutr. 2017 Dec; 20(17):3183-92.

87 Waldum HL, Sørdal Ø, Fossmark R. Proton pump inhibitors (PPIs) may cause gastric cancer - clinical consequences. Scand J Gastroenterol. 2018 Jun;53(6):639-42.

88 Lundell L, Vieth M, Gibson F, Nagy P, Kahrilas PJ. Systematic review: the effects of longterm proton pump inhibitor use on serum gastrin levels and gastric histology. Aliment Pharmacol Ther. 2015 Sep;42(6):649-63.

89 Song H, Zhu J, Lu D. Long-term proton pump inhibitor (PPI) use and the development of gastric pre-malignant lesions. Cochrane Database Syst Rev. 2014 Dec;(12): CD010623.

90 Attwood SE, Ell C, Galmiche JP, Fiocca R, Hatlebakk JG, Hasselgren B, et al. Long-term safety of proton pump inhibitor therapy assessed under controlled, randomised clinical trial conditions: data from the SOPRAN and LOTUS studies. Aliment Pharmacol Ther. 2015 Jun;41(11):1162-74.

91 Cheung KS, Chan EW, Wong AY, Chen L, Wong IC, Leung WK. Long-term proton pump inhibitors and risk of gastric cancer development after treatment for Helicobacter pylori: a population-based study. Gut. 2018 Jan;67(1):28-35.

92 Brusselaers N, Wahlin K, Engstrand L, Lagergren J. Maintenance therapy with proton pump inhibitors and risk of gastric cancer: a nationwide population-based cohort study in Sweden. BMJ Open. 2017 Oct; 7(10): e017739.

93 Cheung KS, Leung WK. Modification of gastric cancer risk associated with proton pump inhibitors by aspirin after Helicobacter pylori eradication. Oncotarget. 2018 Dec;9(97): 36891-3.

94 Vaezi MF, Yang YX, Howden CW. Complications of Proton Pump Inhibitor Therapy. Gastroenterology. 2017 Jul;153(1):35-48.

95 Nardone G, Rocco A. Chemoprevention of gastric cancer: role of COX-2 inhibitors and other agents. Dig Dis. 2004;22(4):320-6.

96 Thun MJ, Namboodiri MM, Calle EE, Flanders WD, Heath CW Jr. Aspirin use and risk of fatal cancer. Cancer Res. 1993 Mar;53(6): $1322-7$.

97 Epplein M, Nomura AM, Wilkens LR, Henderson BE, Kolonel LN. Nonsteroidal antiinflammatory drugs and risk of gastric adenocarcinoma: the multiethnic cohort study. Am J Epidemiol. 2009 Aug;170(4):507-14.
98 Sørensen HT, Friis S, Nørgård B, Mellemkjaer L, Blot WJ, McLaughlin JK, et al. Risk of cancer in a large cohort of nonaspirin NSAID users: a population-based study. $\mathrm{Br}$ J Cancer. 2003 Jun;88(11):1687-92.

99 Leung WK, Ng EK, Chan FK, Chan WY, Chan KF, Auyeung AC, et al. Effects of longterm rofecoxib on gastric intestinal metaplasia: results of a randomized controlled trial. Clin Cancer Res. 2006 Aug;12(15): 4766-72.

100 Zhang LJ, Wang SY, Huo XH, Zhu ZL, Chu JK, Ma JC, et al. Anti-Helicobacter pylori therapy followed by celecoxib on progression of gastric precancerous lesions. World J Gastroenterol. 2009 Jun 14;15(22):2731-8.

101 Ma Z, Wang W, Jin G, Chu P, Li H. Effect of statins on gastric cancer incidence: a metaanalysis of case control studies. J Cancer Res Ther. 2014 Oct-Dec;10(4):859-65.

102 Singh PP, Singh S. Statins are associated with reduced risk of gastric cancer: a systematic review and meta-analysis. Ann Oncol. 2013 Jul;24(7):1721-30.

103 Chiu HF, Ho SC, Chang CC, Wu TN, Yang CY. Statins are associated with a reduced risk of gastric cancer: a population-based case-control study. Am J Gastroenterol. 2011 Dec;106(12):2098-103.

104 Sugano K, Tack J, Kuipers EJ, Graham DY, El-Omar EM, Miura S, et al.; faculty members of Kyoto Global Consensus Conference. Kyoto global consensus report on Helicobacter pylori gastritis. Gut. 2015 Sep; 64(9):1353-67.

105 Fuccio L, Zagari RM, Eusebi LH, Laterza L, Cennamo V, Ceroni L, et al. Meta-analysis: can Helicobacter pylori eradication treatment reduce the risk for gastric cancer? Ann Intern Med. 2009 Jul;151(2):121-8.

106 Lee YC, Chen TH, Chiu HM, Shun CT, Chiang $\mathrm{H}$, Liu TY, et al. The benefit of mass eradication of Helicobacter pylori infection: a community-based study of gastric cancer prevention. Gut. 2013 May;62(5):676-82.

107 Wong BC, Lam SK, Wong WM, Chen JS, Zheng TT, Feng RE, et al.; China Gastric Cancer Study Group. Helicobacter pylori eradication to prevent gastric cancer in a high-risk region of China: a randomized controlled trial. JAMA. 2004 Jan;291(2): 187-94.

108 Shichijo S, Hirata Y, Niikura R, Hayakawa Y, Yamada A, Ushiku T, et al. Histologic intestinal metaplasia and endoscopic atrophy are predictors of gastric cancer development after Helicobacter pylori eradication. Gastrointest Endosc. 2016 Oct;84(4):618-24.

109 Take S, Mizuno M, Ishiki K, Nagahara Y, Yoshida T, Yokota K, et al. Baseline gastric mucosal atrophy is a risk factor associated with the development of gastric cancer after Helicobacter pylori eradication therapy in patients with peptic ulcer diseases. J Gastroenterol. 2007 Jan;42(S17 Suppl 17):21-7.

110 Weck MN, Brenner H. Association of Helicobacter pylori infection with chronic atro- phic gastritis: meta-analyses according to type of disease definition. Int J Cancer. 2008 Aug;123(4):874-81.

111 Ohata H, Kitauchi S, Yoshimura N, Mugitani K, Iwane M, Nakamura H, et al. Progression of chronic atrophic gastritis associated with Helicobacter pylori infection increases risk of gastric cancer. Int J Cancer. 2004 Mar;109(1):138-43.

112 Cassaro M, Rugge M, Gutierrez O, Leandro G, Graham DY, Genta RM. Topographic patterns of intestinal metaplasia and gastric cancer. Am J Gastroenterol. 2000 Jun;95(6): 1431-8.

113 de Vries AC, van Grieken NC, Looman CW, Casparie MK, de Vries E, Meijer GA, et al. Gastric cancer risk in patients with premalignant gastric lesions: a nationwide cohort study in the Netherlands. Gastroenterology. 2008 Apr;134(4):945-52.

114 Song H, Ekheden IG, Zheng Z, Ericsson J, Nyrén $\mathrm{O}, \mathrm{Ye} \mathrm{W}$. Incidence of gastric cancer among patients with gastric precancerous lesions: observational cohort study in a low risk Western population. BMJ. 2015 Jul; 351:h3867.

115 Rokkas T, Pistiolas D, Sechopoulos P, Robotis I, Margantinis G. The long-term impact of Helicobacter pylori eradication on gastric histology: a systematic review and meta-analysis. Helicobacter. 2007 Nov; 12(s2 Suppl 2):32-8.

116 Wang J, Xu L, Shi R, Huang X, Li SW, Huang $Z$, et al. Gastric atrophy and intestinal metaplasia before and after Helicobacter pylori eradication: a meta-analysis. Digestion. 2011;83(4):253-60.

117 Chen HN, Wang Z, Li X, Zhou ZG. Helicobacter pylori eradication cannot reduce the risk of gastric cancer in patients with intestinal metaplasia and dysplasia: evidence from a meta-analysis. Gastric Cancer. 2016 Jan; 19(1):166-75.

118 Leung WK, Wong IO, Cheung KS, Yeung $\mathrm{KF}$, Chan EW, Wong AY, et al. Effects of Helicobacter pylori Treatment on Incidence of Gastric Cancer in Older Individuals. Gastroenterology. 2018 Jul;155(1):67-75.

119 Fukase K, Kato M, Kikuchi S, Inoue K, Uemura N, Okamoto S, et al.; Japan Gast Study Group. Effect of eradication of Helicobacter pylori on incidence of metachronous gastric carcinoma after endoscopic resection of early gastric cancer: an open-label, randomised controlled trial. Lancet. 2008 Aug;372(9636): 392-7.

120 Jung DH, Kim JH, Chung HS, Park JC, Shin SK, Lee SK, et al. Helicobacter pylori Eradication on the Prevention of Metachronous Lesions after Endoscopic Resection of Gastric Neoplasm: A Meta-Analysis. PLoS One. 2015 Apr;10(4):e0124725.

121 Choi IJ, Kook MC, Kim YI, Cho SJ, Lee JY, Kim CG, et al. Helicobacter pylori Therapy for the Prevention of Metachronous Gastric Cancer. N Engl J Med. 2018 Mar;378(12): 1085-95. 
122 Pan KF, Zhang L, Gerhard M, Ma JL, Liu $\mathrm{WD}$, Ulm K, et al. A large randomised controlled intervention trial to prevent gastric cancer by eradication of Helicobacter pylori in Linqu County, China: baseline results and factors affecting the eradication. Gut. 2016 Jan;65(1):9-18.

123 Lee YC, Chen TH, Chiu HM, Shun CT, Chiang H, Liu TY, et al. The benefit of mass eradication of Helicobacter pylori infection: a community-based study of gastric cancer prevention. Gut. 2013 May;62(5):676-82.

124 Zeng M, Mao XH, Li JX, Tong WD, Wang B, Zhang YJ, et al. Efficacy, safety, and immunogenicity of an oral recombinant Helicobacter pylori vaccine in children in China: a randomised, double-blind, placebo-controlled, phase 3 trial. Lancet. 2015 Oct; 386(10002):1457-64.

125 Malfertheiner P, Selgrad M, Wex T, Romi B, Borgogni E, Spensieri F, et al. Efficacy, immunogenicity, and safety of a parenteral vaccine against Helicobacter pylori in healthy volunteers challenged with a Cag-positive strain: a randomised, placebo-controlled phase 1/2 study. Lancet Gastroenterol Hepatol. 2018 Oct;3(10):698-707.

126 Sakitani K, Nishizawa T, Arita M, Yoshida S, Kataoka Y, Ohki D, et al. Early detection of gastric cancer after Helicobacter pylori eradication due to endoscopic surveillance. Helicobacter. 2018 Aug;23(4):e12503.

127 Oda I, Hoteya S, Fujishiro M. Status of Helicobacter pylori infection and gastric mucosal atrophy in patients with gastric cancer: Analysis based on the Japan Endoscopy Database. Dig Endosc. 2019 Jan;31(1):103.

128 Dinis-Ribeiro M, Areia M, de Vries AC, Marcos-Pinto R, Monteiro-Soares M, O'Connor A, et al.; European Society of Gastrointestinal Endoscopy; European Helicobacter Study Group; European Society of Pathology; Sociedade Portuguesa de Endoscopia Digestiva. Management of precancerous conditions and lesions in the stomach (MAPS): guideline from the European Society of Gastrointestinal Endoscopy (ESGE), European Helicobacter Study Group (EHSG), European Society of Pathology (ESP), and the Sociedade Portuguesa de Endoscopia Digestiva (SPED). Endoscopy. 2012 Jan;44(1):74-94.

129 den Hoed CM, Holster IL, Capelle LG, de Vries AC, den Hartog B, Ter Borg F, et al. Follow-up of premalignant lesions in patients at risk for progression to gastric cancer. Endoscopy. 2013;45(4):249-56.

130 Li D, Bautista MC, Jiang SF, Daryani P, Brackett M, Armstrong MA, et al. Risks and Predictors of Gastric Adenocarcinoma in Patients with Gastric Intestinal Metaplasia and Dysplasia: A Population-Based Study. Am J Gastroenterol. 2016 Aug;111(8):110413.

131 den Hollander WJ, Holster IL, den Hoed CM, Capelle LG, Tang TJ, Anten MP, et al. Surveillance of premalignant gastric lesions: a multicentre prospective cohort study from low incidence regions. Gut. 2019 Apr;68(4): 585-93.

132 Dixon MF, Genta RM, Yardley JH, Correa P. Classification and grading of gastritis. The updated Sydney System. International Workshop on the Histopathology of Gastritis, Houston 1994. Am J Surg Pathol. 1996 Oct;20(10):1161-81.

133 Rugge M, Genta RM; OLGA Group. Staging gastritis: an international proposal. Gastroenterology. 2005 Nov;129(5):1807-8.

134 Rugge M, Meggio A, Pennelli G, Piscioli F, Giacomelli L, De Pretis G, et al. Gastritis staging in clinical practice: the OLGA staging system. Gut. 2007 May;56(5):631-6.

135 Capelle LG, de Vries AC, Haringsma J, Ter Borg F, de Vries RA, Bruno MJ, et al. The staging of gastritis with the OLGA system by using intestinal metaplasia as an accurate alternative for atrophic gastritis. Gastrointest Endosc. 2010 Jun;71(7):1150-8.

136 Rugge M, de Boni M, Pennelli G, de Bona M, Giacomelli L, Fassan M, et al. Gastritis OLGA-staging and gastric cancer risk: a twelveyear clinico-pathological follow-up study. Aliment Pharmacol Ther. 2010 May;31(10): 1104-11.

137 Leja M, Funka K, Janciauskas D, Putnins V, Ruskule A, Kikuste I, et al. Interobserver variation in assessment of gastric premalignant lesions: higher agreement for intestinal metaplasia than for atrophy. Eur J Gastroenterol Hepatol. 2013 Jun;25(6):694-9.

138 Isajevs S, Liepniece-Karele I, Janciauskas D, Moisejevs G, Putnins V, Funka K, et al. Gastritis staging: interobserver agreement by applying OLGA and OLGIM systems. Virchows Arch. 2014 Apr;464(4):403-7.

139 Rugge M, Meggio A, Pravadelli C, Barbareschi M, Fassan M, Gentilini M, et al. Gastritis staging in the endoscopic follow-up for the secondary prevention of gastric cancer: a 5 -year prospective study of 1755 patients. Gut. 2019 Jan;68(1):11-7.

140 Rugge M, Genta RM, Fassan M, Valentini E, Coati I, Guzzinati S, et al. OLGA Gastritis Staging for the Prediction of Gastric Cancer Risk: A Long-term Follow-up Study of 7436 Patients. Am J Gastroenterol. 2018 Nov; 113(11):1621-8.

141 de Vries AC, Haringsma J, Kuipers EJ. The detection, surveillance and treatment of premalignant gastric lesions related to Helicobacter pylori infection. Helicobacter. 2007 Feb;12(1):1-15.

142 de Vries AC, Haringsma J, de Vries RA, Ter Borg F, van Grieken NC, Meijer GA, et al. Biopsy strategies for endoscopic surveillance of pre-malignant gastric lesions. Helicobacter. 2010 Aug;15(4):259-64.

143 O'Connor A, McNamara D, O’Moráin CA. Surveillance of gastric intestinal metaplasia for the prevention of gastric cancer. Cochrane Database Syst Rev. 2013 Sep;(9):CD009322.

144 Hassan C, Zullo A, Di Giulio E, Annibale B, Lahner E, De Francesco V, et al. Cost-effec- tiveness of endoscopic surveillance for gastric intestinal metaplasia. Helicobacter. 2010 Jun;15(3):221-6.

145 Areia M, Dinis-Ribeiro M, Rocha Gonçalves F. Cost-utility analysis of endoscopic surveillance of patients with gastric premalignant conditions. Helicobacter. 2014 Dec;19(6): $425-36$.

146 Lahner E, Hassan C, Esposito G, Carabotti M, Zullo A, Dinis-Ribeiro M, et al. Cost of detecting gastric neoplasia by surveillance endoscopy in atrophic gastritis in Italy: A low risk country. Dig Liver Dis. 2017 Mar;49(3): 291-6.

147 Kanesaka T, Lee TC, Uedo N, Lin KP, Chen HZ, Lee JY, et al. Computer-aided diagnosis for identifying and delineating early gastric cancers in magnifying narrow-band imaging. Gastrointest Endosc. 2018 May;87(5): 1339-44.

148 Watabe H, Mitsushima T, Yamaji Y, Okamoto M, Wada R, Kokubo T, et al. Predicting the development of gastric cancer from combining Helicobacter pylori antibodies and serum pepsinogen status: a prospective endoscopic cohort study. Gut. 2005 Jun; 54(6):764-8.

149 Oishi Y, Kiyohara Y, Kubo M, Tanaka K, Tanizaki $Y$, Ninomiya T, et al. The serum pepsinogen test as a predictor of gastric cancer: the Hisayama study. Am J Epidemiol. 2006 Apr;163(7):629-37.

150 Ikeda F, Shikata K, Hata J, Fukuhara M, Hirakawa $\mathrm{Y}$, Ohara $\mathrm{T}$, et al. Combination of Helicobacter pylori Antibody and Serum Pepsinogen as a Good Predictive Tool of Gastric Cancer Incidence: 20-Year Prospective Data From the Hisayama Study. J Epidemiol. 2016 Dec;26(12):629-36.

151 Terasawa T, Nishida H, Kato K, Miyashiro I, Yoshikawa T, Takaku R, et al. Prediction of gastric cancer development by serum pepsinogen test and Helicobacter pylori seropositivity in Eastern Asians: a systematic review and meta-analysis. PLoS One. 2014 Oct;9(10):e109783.

152 Miki K. Gastric cancer screening using the serum pepsinogen test method. Gastric Cancer. 2006;9(4):245-53.

153 Yoshihara M, Hiyama T, Yoshida S, Ito M Tanaka S, Watanabe Y, et al. Reduction in gastric cancer mortality by screening based on serum pepsinogen concentration: a casecontrol study. Scand J Gastroenterol. 2007 Jun;42(6):760-4.

154 Huang YK, Yu JC, Kang WM, Ma ZQ, Ye X Tian SB, et al. Significance of Serum Pepsinogens as a Biomarker for Gastric Cancer and Atrophic Gastritis Screening: A Systematic Review and Meta-Analysis. PLoS One. 2015 Nov; 10(11):e0142080.

155 Yanaoka K, Oka M, Ohata H, Yoshimura N, Deguchi H, Mukoubayashi C, et al. Eradication of Helicobacter pylori prevents cancer development in subjects with mild gastric atrophy identified by serum pepsinogen levels. Int J Cancer. 2009 Dec;125(11):2697-703. 
156 Lomba-Viana R, Dinis-Ribeiro M, Fonseca F, Vieira AS, Bento MJ, Lomba-Viana H. Serum pepsinogen test for early detection of gastric cancer in a European country. Eur J Gastroenterol Hepatol. 2012 Jan;24(1):3741.

157 Zhang X, Xue L, Xing L, Wang J, Cui J, Mi J, et al. Low serum pepsinogen I and pepsinogen I/II ratio and Helicobacter pylori infection are associated with increased risk of gastric cancer: 14-year follow up result in a rural Chinese community. Int J Cancer. 2012 Apr; 130(7):1614-9.

158 Zagari RM, Rabitti S, Greenwood DC, Eusebi LH, Vestito A, Bazzoli F. Systematic review with meta-analysis: diagnostic performance of the combination of pepsinogen, gastrin-17 and anti-Helicobacter pylori antibodies se- rum assays for the diagnosis of atrophic gastritis. Aliment Pharmacol Ther. 2017 Oct; 46(7):657-67.

159 Yeh JM, Hur C, Ward Z, Schrag D, Goldie SJ. Gastric adenocarcinoma screening and prevention in the era of new biomarker and endoscopic technologies: a cost-effectiveness analysis. Gut. 2016 Apr;65(4): 563-74.

160 den Hoed CM, van Eijck BC, Capelle LG, van Dekken H, Biermann K, Siersema PD, et al. The prevalence of premalignant gastric lesions in asymptomatic patients: predicting the future incidence of gastric cancer. Eur J Cancer. 2011 May;47(8):1211-8.

161 Areia M, Spaander MC, Kuipers EJ, Dinis-Ribeiro M. Endoscopic screening for gastric cancer:A cost-utility analysisfor countries with an intermediate gastric cancer risk. United European Gastroenterol J.2018 Mar;6(2):192-202.

162 Tepes B, Seruga M, Vujasinovic M, Urlep D, Ljepovic L, Brglez JN, et al. Premalignant gastric lesions in patients included in $\mathrm{Na}$ tional colorectal cancer screening. Radiol Oncol. 2017 Dec;52(1):7-13.

163 Malfertheiner P, Megraud F, O'Morain CA, Gisbert JP, Kuipers EJ, Axon AT, et al.; European Helicobacter and Microbiota Study Group and Consensus panel. Management of Helicobacter pylori infection-the Maastricht V/Florence Consensus Report. Gut. 2017 Jan;66(1):6-30.

164 Rugge M, Genta RM, Di Mario F, El-Omar EM, El-Serag HB, Fassan M, et al. Gastric Cancer as Preventable Disease. Clin Gastroenterol Hepatol. 2017 Dec;15(12):1833-43. 